$2019,20(1)$, pp. 121 - 132, DOI: 10.18038/aubtda.410141

\title{
EVALUATING ETHYLENE PROPYLENE DIENE MONOMER RUBBER FOR DYNAMIC APPLICATIONS INSTEAD OF NATURAL RUBBER
}

\author{
Ayşe Tuğba BAYRAM ${ }^{1,2}$, Bağdagül KARAAĞAÇ ${ }^{1,3}$, Haluk KONYALI ${ }^{2}$ \\ ${ }^{1}$ Polymer Science and Technology Dept., Kocaeli University, Kocaeli, Turkey \\ 2 Tekno Rubber Co., Gebze-Kocaeli, Turkey \\ ${ }^{3}$ Chemical Engineering Dept., Kocaeli University, Kocaeli, Turkey
}

\begin{abstract}
Natural Rubber (NR) has been used in dynamic applications for many years. NR has satisfactory resilience, vibration, and fatigue properties. Besides all these good properties, NR has quite poor aging resistance; also its service temperature is limited to about $90{ }^{\circ} \mathrm{C}$. Improving aging characteristics of NR is a common problem for both rubber industry and academy. Nowadays, especially automotive industry has been focused on thermally resistant static and dynamic rubber based materials in new generation automobiles because of current strict emission regulations. There are a lot of attempts to improve service conditions of NR however; they are not comparable yet, with alternative saturated rubbers such as ethylene propylene diene monomer rubber (EPDM). In this study, a new grade EPDM, which had a high molecular weight, narrow molecular weight distribution, and tailor-made chain structure, has been studied in terms of rheological, mechanical, dynamic mechanical, aging, and low temperature properties for target dynamic applications. Especially possible service temperature and dynamic performance of EPDM were compared to that of NR based reference. It was concluded that, EPDM may be an assertive competitor to NR, if its chain structure is modified correctly.
\end{abstract}

Keywords: Rubber, EPDM, Natural rubber, NR, Dynamic Properties

\section{INTRODUCTION}

Natural rubber (NR) is the most preferred raw material for many industrial dynamic applications such as anti-vibrating structures, shock mouths, bridge bearings, and automobile parts $[1,2]$. Hard service conditions of such materials also require good aging resistance and high temperature performance [3]. Because of limited service temperature, low ozone resistance, and relatively worse aging behaviour of NR based materials, researchers and industry, especially automotive industry, focus on alternative materials for fulfilling current demands in new generation automobiles and for new emission regulations. There are lots of attempts to improve service conditions of NR; but still NR is not comparable to saturated rubbers such as ethylene propylene diene monomer rubber (EPDM), in terms of service conditions.

One of the attempts for improving both aging and dynamic properties of NR is adjusting the curing system. In 1963, Stratton and Ferry evaluated different vulcanization systems for improving dynamicmechanical properties of NR [4]. Peroxide vulcanization, $\gamma$-radiation, vulcanization by tetramethyl thiuram disulphide (TMTD) as sulphur donor, and various sulphur/accelerator ratios in sulphur vulcanization were studied, comparatively. Sulphur vulcanization with high sulphur/accelerator ratio was found more effective for dynamic applications due to high fatigue resistance. Fan et al. studied effect of reversion on dynamic properties for gum and carbon black filled NR vulcanizates by comparing conventional (CV), semi-efficient (semi-EV), and efficient (EV) vulcanization systems for the same crosslink densities [5]. In dynamic mechanical thermal analysis (DMTA), higher glass transition temperatures $(\mathrm{Tg})$ and damping factor $(\tan \delta)$ values are obtained for filled NR and CV system. It was concluded that, reversion had a major effect on dynamic properties of NR.

*Corresponding Author: bkaraagac@gmail.com

Received: 27.03.12018 Accepted: 23.01.2019 
Another issue on improving NR for high temperature dynamic applications is main chain modification. Simma et al. tried to improve thermal stability and aging resistance of a model NR skim compound by hydrogenation in latex form via diimid reduction [6]. They used a mixed vulcanization system containing peroxide, zinc oxide, stearic acid, and organic accelerators. It was concluded that, hydrogenated NR compounds can exhibit moderate thermal stability between that of NR and EPDM. Hydrogenated NR could also retain its mechanical properties after aging, and ozone resistance of it was significantly higher than NR. Akinlabi et al. used low molecular weight epoxidized natural rubber (ENR) for improving thermal properties of NR blends [7]. It was concluded that total amount of saturation in the rubber matrix improved aging behaviour of NR based materials; higher ENR incorporation gave enhanced thermal resistance. Lu et al. studied on enhancing high temperature damping properties of ENR by using ENR/diallyl phthalate pre-polymer binary blends [8]. They envisaged that peroxides could trigger free radical reactions both within and between two phases and phase compatibility was enhanced due to co-vulcanization reactions.

Due to its saturated chemical structure, EPDM has excellent thermal and ozone resistance. Thanks to these properties, EPDM has long been a target for dynamic application instead of NR. However, it is well known that EPDM has poorer mechanical properties than NR; sometimes this has key importance for specific applications. Ginic-Markovich et al. investigated viscoelastic properties of gum and filled EPDM based automotive windowseal compounds by using a dynamic mechanical analyzer (DMA) over a wide range of temperature, strain, and frequency [9]. They tried to understand filler effect on EPDM's dynamic properties. This study also defined appropriate test conditions for testing viscoelastic properties of EPDM. Mao et al. studied damping properties of EPDM after blending with aliphatic hydrocarbon resins [10]. In the same study, EPDM was blended with acrylonitrile butadiene rubber (NBR) in various ratios. It was concluded that damping properties were improved in the presence of various resins as well as NBR incorporation. NBR also improved damping properties of EPDM for an extended temperature range. Nabil at al. studied dynamic mechanical properties of NR/recycled EPDM blends as well as curing characteristics and mechanical properties [11]. They focused on accelerator system optimization to improve compatibility of these two rubbers. Better curative distribution, higher crosslink density levels, and therefore satisfactory damping properties were obtained by using tetramethyl thiuram disulphide (TMTD). Dynamic behavior of short aramid fiber-filled NR and EPDM composites were studied by Hintze et al. [12]. Two different types of short aramid fibers were used to reinforce peroxidecured EPDM and sulphur-cured NR matrices. It was found that short fibers could contribute to have improved crack-growth resistance and dynamic mechanical behavior of the composites.

Spanos et al. studied the alternative EPDM, which is focused on in this study, in NR/EPDM blends containing three different sulphur ratios [13]. They also prepared NR reference formulations having the same sulphur ratios for investigating the effect of alternative EPDM incorporation. Rheological, physical, mechanical, aging, and fatigue properties were studied as well as dynamic properties by using rubber process analyzer (RPA). It was concluded that blending NR and EPDM provides higher thermal aging resistance and longer material life time whereas fatigue properties were also satisfactory.

In this study, possible usage of a special grade EPDM, which had a high molecular weight, narrow molecular weight distribution, and tailor-made chain structure, was evaluated for target dynamic applications, in detail. Rheological, mechanical, and dynamic-mechanical properties of new EPDM based materials were evaluated by comparing with that of NR based materials (NR/BR blend). Evaluations have also been carried out for a reference EPDM compound which was based on a similar ENB content of rubber matrix. Besides, alternative EPDM compound has been varied by process oil incorporation to overcome poor processability properties as well as elevated sulphur amounts to evaluate effect of crosslink density. Low temperature properties of all the formulations were also investigated for filling the gap in the literature, systematically. 


\section{EXPERIMENTAL}

\subsection{Materials}

Natural rubber (CV 60) was supplied from Baria Rubber Co. (Vietnam) with 60 \pm 5 MU of Mooney viscosity (@100 $\left.10{ }^{\circ} \mathrm{C} \mathrm{ML}(1+8)\right), 82$ of plasticity retention index, and $0.019 \%$ of dirt content. Butadiene rubber (BR) was supplied from Voronezh (Russia) having 44 $\pm 5 \mathrm{MU}$ of Mooney viscosity (@100 ${ }^{\circ} \mathrm{C} \mathrm{ML}$ $(1+4)$ ). Alternative EPDM (Keltan 9565Q), which is the focus of present study, was obtained from Lanxess (USA). Conventional (reference) EPDM (KEP 2380) having similar ENB with alternative one were obtained from Kumho (Korea). KEP 2380 has $82 \pm 5$ of Mooney viscosity $\left(@ 125^{\circ} \mathrm{C}\right.$ ML $\left.(1+8)\right)$, 53.5-57.5\% ethylene content, and 5.2-6.2\% ENB content. Properties those of Keltan 9565Q (alternative) were $67 \mathrm{MU}\left(@ 150^{\circ} \mathrm{C} \mathrm{ML}(1+8)\right), 62 \%$, and 5.5\%, respectively. Keltan 9565Q has also 50 phr extender oil to provide satisfactory process conditions. Carbon black FEF550 (DBP: $121 \pm 6 \mathrm{mg}\left(100 \mathrm{~L}^{-1}\right.$ and surface area: $39 \pm 6 \mathrm{~m}^{2} \mathrm{~g}^{-1}$ ) obtained from OMSK (Russia) was used as filler. Heavy paraffinic oil and naphthenic oil were obtained from Shell (Turkey) and Petroyağ (Turkey), respectively. Paraffinic oil has $486.760 \mathrm{~mm}^{2} \mathrm{~s}^{-1}$ of viscosity $\left(@ 40^{\circ} \mathrm{C}\right)$ and $906.3 \mathrm{kgm}^{-3}$ of density, whereas naphthenic oil has 22 $\mathrm{mm}^{2} \mathrm{~s}^{-1}$ of viscosity and $902 \mathrm{kgm}^{-3}$ of density. The other compound ingredients are commercially used chemicals for rubber and tire industries and supplied from various companies.

\subsection{Methods}

Rubber compounds were prepared in a $1.5 \mathrm{~L}$ internal mixer (Werner\&Pfleider) and a two-roll mill, subsequently. Main compound containing rubber(s), reinforcing filler, process oil, activators, and stabilizers, was prepared in the internal mixer. Compound was dropped at $120^{\circ} \mathrm{C}$. After 1 min wrapping on two-roll mill, curatives were added; compounding continued for further 2 minutes at various mill gaps.

Curing characteristics were obtained by using a moving die rheometer (MDR, Alpha Technologies MDR $2000)$ at $165^{\circ} \mathrm{C}$ according to ISO $6502 . \mathrm{M}_{\mathrm{L}}, \mathrm{M}_{\mathrm{H}}, \mathrm{ts}_{2}, \mathrm{t}_{50}$, $\mathrm{t}_{90}$ values were measured; cure extent and cure rate index (CRI) were calculated from the values according to Equation 1 and Equation 2, respectively.

$$
\begin{aligned}
& \text { Cure extent }=\mathrm{M}_{\mathrm{H}}-\mathrm{M}_{\mathrm{L}} \\
& \mathrm{CRI}=100 /\left(\mathrm{t}_{90}-\mathrm{ts}_{2}\right)
\end{aligned}
$$

Vulcanization and moulding were carried out on a hydraulic hot pres (Panstone) at $165^{\circ} \mathrm{C}$ for their respective optimum cure times obtained from rheometer curves. Test specimens were cut from the molded sheets in required dimensions by standard blades. Tensile strength, elongation at break, Young's modulus, tensile modulus, and tear strength are represented as mechanical properties. These properties were measured according to ISO 37 by using universal tensile tester (Zwick/Roell $2.5 \mathrm{kN}$ ). Hardness was determined according to DIN ISO 7619-1 in Shore A. Abrasion resistance was measured according to the ISO 4649. Compression set test was carried out according to DIN 53508. All the vulcanizates were subjected to thermal aging in an air circulating oven at $70^{\circ} \mathrm{C}$ for $24 \mathrm{~h}$ and $72 \mathrm{~h}$. Thermal aging at $100^{\circ} \mathrm{C}$ for $72 \mathrm{~h}$ was also performed to evaluate hard conditions for the materials. Some of the mechanical tests were repeated after thermal aging to calculate retention in the properties; compression set test was also carried out for all the aging conditions. Ozone resistance was measured for $25^{\circ} \mathrm{C}$ and $60 \%$ relative humidity. 200 pphm ozone concentration was applied for $20 \%$ strained samples during $48 \mathrm{~h}$.

Rebound resilience was measured according to DIN 53512 by using a resilience elasticity tester (Karl Frank GMBH). In this method, we can readily determine percentage rebound of the materials having 30-85 Shore A hardness. Strain is applied to the sample via a free-fall indentor. Rebound resilience is defined as the ratio between retained distance and initial distance of the indentor. However, this method gives only premature information about material elasticity. Heat build-up test was performed according to ISO 4666 by using Goodrich Flexometer (Doli). In this test, a cyclic deformation is applied to test sample under compressive load with specific amplitude and at a constant temperature. After the test 
period, temperature increase and the final inner temperature of the sample are reported. Temperature increment is related to heat build-up of the material under dynamic conditions and represents hysteretic loss. Viscoelastic properties of the vulcanizates were determined by using a dynamic mechanical analyzer (Metravib DMA50). Tests were performed as temperature sweep and frequency sweep in tension mode. Swept temperature range was $30-200{ }^{\circ} \mathrm{C}$ with a heating rate of $3^{\circ} \mathrm{Cmin}-1$; frequency was kept constant as $1 \mathrm{~Hz}$ during the test. For frequency sweep, $1-100 \mathrm{~Hz}$ range was investigated at $60^{\circ} \mathrm{C}$, considering mean temperature of the material under dynamic conditions.

Temperature retraction (TR) test was performed to determine low temperature properties by using a temperature retraction tester (Elastocon) according to ISO 2921. In TR test, vulcanized sample is conditioned at $-70^{\circ} \mathrm{C}$ for 10 minutes and under $50 \%$ strain. Then, cabin temperature is increased by $1^{\circ} \mathrm{Cmin}-1$. TR property is defined in terms of temperatures at specified retraction ratios.

\section{RESULTS AND DISCUSSION}

Help to evaluate dynamic properties of EPDM based compounds, two different grades of EPDM and NR/BR based compounds were compared in detail. All the compound formulations are given in Table 1. NR-60 represents a reference formulation used in traditional dynamic applications. The formulation was designed considering similar modulus relative to EPDM based compounds. EPDM-0 formulation is based on KEP 2380 which has similar ENB content of Keltan 9565Q. EPDM-A formulations are based on Keltan 9565Q and likewise it contains $50 \mathrm{phr}$ extender oil. This is the reason that rubber matrix of EPDM-A formulations is defined as $150 \mathrm{phr}$, and also EPDM- 0 formulation contains $50 \mathrm{phr}$ process oil whereas EPDM-As do not. EPDM-A5, EPDM-A10, EPDM-A20, and EPDM-A30 formulations contain additional paraffinic process oil to overcome poor processability and investigate the effects of this solution on the material properties. EPDM-AHS and EPDM-ALS formulations were designed to gain an understanding of crosslink density effect in EPDM-A. EPDM-AHS has the sulphur ratio as 0.75 phr higher than EPDM-A, whereas EPDM-ALS has it as 0.75 phr lower. The other compounding ingredients were kept as same for studying their own unique contributions of the selected variables.

Table 1. Compound formulations (in phr)

\begin{tabular}{|c|c|c|c|c|c|c|c|c|c|}
\hline Compound & $\begin{array}{l}8 \\
\stackrel{0}{1} \\
\tilde{L}\end{array}$ & 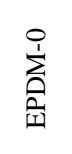 & 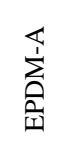 & 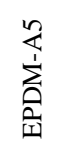 & 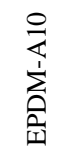 & 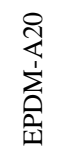 & 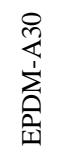 & 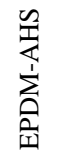 & 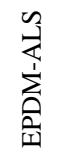 \\
\hline EPDM & & 100 & 150 & 150 & 150 & 150 & 150 & 150 & 150 \\
\hline NR & 70 & & & & & & & & \\
\hline BR & 30 & & & & & & & & \\
\hline Carbon black & 54 & 80 & 80 & 80 & 80 & 80 & 80 & 80 & 80 \\
\hline Process oil & & 50 & 0 & 5 & 10 & 20 & 30 & 0 & 0 \\
\hline Zinc oxide & 10 & 5 & 5 & 5 & 5 & 5 & 5 & 5 & 5 \\
\hline Stearic acid & 1 & 1 & 1 & 1 & 1 & 1 & 1 & 1 & 1 \\
\hline IPPD & 3 & & & & & & & & \\
\hline TMQ & 2 & & & & & & & & \\
\hline Wax & 2 & & & & & & & & \\
\hline CBS & 1 & 2 & 2 & 2 & 2 & 2 & 2 & 2 & 2 \\
\hline ZBEC & & 1.5 & 1.5 & 1.5 & 1.5 & 1.5 & 1.5 & 1.5 & 1.5 \\
\hline ZTDP & & 2.5 & 2.5 & 2.5 & 2.5 & 2.5 & 2.5 & 2.5 & 2.5 \\
\hline MBT & & 1.5 & 1.5 & 1.5 & 1.5 & 1.5 & 1.5 & 1.5 & 1.5 \\
\hline Sulphur & 2.5 & 1.75 & 1.75 & 1.75 & 1.75 & 1.75 & 1.75 & 2.5 & 1 \\
\hline
\end{tabular}

\subsection{Rheological Tests}

Important rheological test results and calculated properties (cure extent and CRI) are given in Table 2. As predicted, EPDM based and NR based compounds have distinct rheological properties. CRI of NR-60 is 
almost two times more than EPDM-A and its less oil containing derivatives. Even, it is fivefold of EPDM0 . This is attributed to NR's chemical structure and high level of unsaturation. However, we can readily evaluate the after-cure properties of NR-60, EPDM-0, and EPDM-A materials considering their cure extent levels. In case of higher sulphur content, higher cure extent existed; lower sulphur content gave low crosslink cure extent level, as expected. For oil containing EPDM-A derivatives, $\mathrm{M}_{\mathrm{L}}$ values virtually followed a contributive trend to improve processing conditions of EPDM-A formulation. EPDM-A and its derivatives were also found to be more scorchier. This is intuitively assigned to hard mixing of Keltan 9565Q.

\subsection{Physical and Mechanical Properties}

As it is well-known, another facet of traditional EPDM is quite poor mechanical properties relative to $\mathrm{NR}$, besides limited dynamic properties. It is possible to increase the strength of it to various deformations by using some reinforcing materials; but also too low crystallization ability of EPDM restricts the improvements. Increasing the chain linearity is intuitively thought to be a good solution to providing stronger vulcanizates. Tensile test results of all the vulcanizates are given in Table 3 , as well as tear strength, abrasion resistance, and hardness of the same ones. When tensile strength values are examined, it could be stated that, EPDM-A formulation exhibits a sufficient mechanical strength with only $16 \%$ deviation from NR based reference formulation. This can be attributed to more linear molecular structure of alternative EPDM than that of traditional EPDM. Results coincide with the current limited literature [13]. Oil incorporation deteriorate tensile properties of EPDM-A, as expected; $10 \mathrm{phr}$ or more oil content exhibit inappropriate tensile strength values for usual applications, instead of NR. When we evaluate sulphur arrangement in EPDM-A formulation, higher sulphur level a derivative of it (EPDM-AHS) has $2 \mathrm{MPa}$ lower a tensile strength. Crosslink density increment always improves modulus of the vulcanizates; but sometimes it cannot be met this change in tensile strength accordingly. This is attributed to formation of various types of crosslinks.

Table 2. Rheological test results

\begin{tabular}{|c|c|c|c|c|c|c|c|c|c|}
\hline Compound & $\begin{array}{l}8 \\
0 \\
\text { 岁 } \\
Z\end{array}$ & 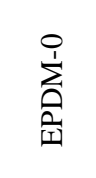 & 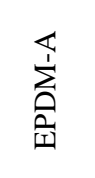 & $\frac{\sum_{i}^{n}}{\sum_{i=1}^{n}}$ & 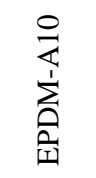 & 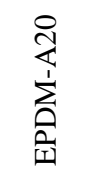 & 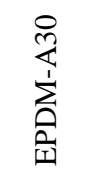 & 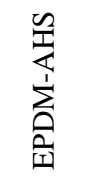 & 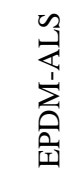 \\
\hline $\mathrm{M}_{\mathrm{L}}(\mathrm{dNm})$ & 1.97 & 1.50 & 3.90 & 3.52 & 3.18 & 2.83 & 2.54 & 4.32 & 4.49 \\
\hline $\mathrm{M}_{\mathrm{H}}(\mathrm{dNm})$ & 16.43 & 17.23 & 17.37 & 16.50 & 14.97 & 13.50 & 12.00 & 21.10 & 16.43 \\
\hline ts2 (min) & 1.85 & 0.98 & 0.77 & 0.80 & 0.83 & 0.97 & 1.05 & 0.70 & 0.98 \\
\hline $\mathrm{t}_{90}(\mathrm{~min})$ & 3.65 & 9.98 & 6.02 & 6.88 & 6.92 & 9.70 & 11.03 & 17.17 & 8.17 \\
\hline Cure extent $(\mathrm{dNm})$ & 14.47 & 15.73 & 13.47 & 12.98 & 11.78 & 10.67 & 9.46 & 16.78 & 11.94 \\
\hline CRI & 55.6 & 11.1 & 19.0 & 16.4 & 16.5 & 11.5 & 10.0 & 6.1 & 13.9 \\
\hline
\end{tabular}

Table 3. Physical and mechanical properties of the vulcanizates

\begin{tabular}{|c|c|c|c|c|c|c|c|c|c|}
\hline Compound & $\begin{array}{l}8 \\
\stackrel{0}{1} \\
\stackrel{\alpha}{z} \\
\text { z }\end{array}$ & 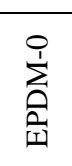 & 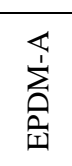 & 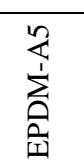 & 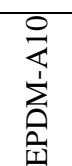 & 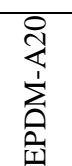 & 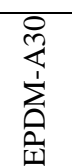 & 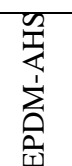 & 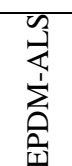 \\
\hline Tensile strength (MPa) & 19.1 & 12.6 & 15.9 & 15.0 & 13.8 & 12.7 & 11.1 & 14.0 & 15.3 \\
\hline Elongation at break $(\%)$ & 551 & 406 & 469 & 408 & 459 & 477 & 465 & 313 & 471 \\
\hline $100 \%$ Modulus (MPa) & 2.4 & 3.2 & 2.8 & 3.5 & 2.7 & 2.2 & 1.9 & 4.2 & 2.9 \\
\hline Tear strength $\left(\mathrm{kgfcm}^{-1}\right)$ & 19.9 & 7.6 & 5.8 & 5.6 & 5.5 & 5.1 & 5.5 & 5.8 & 9.3 \\
\hline Abrasion $\left(\mathrm{mm}^{3}\right)$ & 152 & 208 & 121 & 130 & 147 & 154 & 176 & 119 & 127 \\
\hline Hardness (Shore A) & 67 & 62 & 62 & 61 & 58 & 56 & 53 & 67 & 62 \\
\hline
\end{tabular}


Despite the good tensile strength, tear strength values do not correspond to that of NR-60 formulation. Comparing NR-60 and EPDM based ones, 74\% an average loss is followed up by EPDM vulcanizates. Moreover, alternative EPDM based formulations have the lowest test results even from traditional EPDM reference. None but, 37\% an increase could be gotten by low sulphur loading (EPDM-ALS formulation).

Indeed, comparing the rubber compounds which has equivalent hardness and modulus values is better for evaluating dynamic properties in each other. This is the main reason to adjust equivalent hardness values of reference and alternative compounds. As it is seen from Table 3, oil incorporation causes a systematic drop in hardness, as expected. On the other hand, higher sulphur level gives high modulus, so high hardness as unsatisfactory level. If we compare abrasion resistance of all the vulcanizates, it is concluded that EPDM-A and EPDM-A5 exhibit excellent performance relative to both references. Abrasion resistance is usually affected by hardness, filler dispersion, and chemical structure of rubber. In this respect, knowing that the other parameters are almost constant, it can be said that alternative EPDM is solely resistant to abrasion due to its own linear and long chain sequence. However, oil incorporation causes a systematic increase in abrasion loss due to intuitive higher viscous content of the material.

\subsection{Aging Properties}

Regardless of the fact that NR is an unrivalled raw material for dynamic applications, it has limited working temperature and thermal aging resistance. In this study, most important properties, which are focused on, are aging properties and dynamic properties of the designed compounds. Therefore, alternative EPDM has been marked for its advantageous aging properties as well as its satisfactory dynamic properties. Thermal aging was performed at $70^{\circ} \mathrm{C}$ and $100^{\circ} \mathrm{C}$ for evaluating the property retention of the vulcanizates at both standard and extreme aging conditions. Changes in tensile strength, elongation at break and hardness values after thermal aging are given in Table 4. Positive values represent increasing by aging while negative ones do decreasing.

Table 4. Percentage retentions in some physical and mechanical properties after thermal aging

\begin{tabular}{|c|c|c|c|c|c|c|c|c|c|}
\hline Compound & $\begin{array}{l}\stackrel{8}{0} \\
\stackrel{1}{\not} \\
\text { Z }\end{array}$ & $\sum_{\text {II }}^{\sum_{1}^{1}}$ & 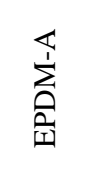 & 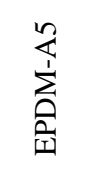 & 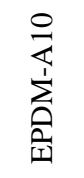 & 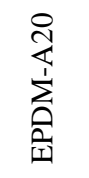 & 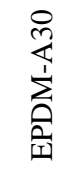 & 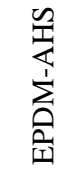 & 空 \\
\hline & \multicolumn{9}{|c|}{ After thermal aging at $70^{\circ} \mathrm{C}$ for $70 \mathrm{~h}$} \\
\hline Tensile strength & -10.8 & 0 & -3.7 & -7.2 & 0 & 1.5 & 5.6 & 0 & 1.9 \\
\hline Elongation at break & -4.2 & -3.2 & -12.4 & -2.2 & 0.9 & 0 & 1.3 & -4.5 & -1.9 \\
\hline \multirow[t]{2}{*}{ Hardness } & 2 & 1 & 0 & 1 & 1 & 1 & 1 & 1 & 0 \\
\hline & \multicolumn{9}{|c|}{ After thermal aging at $100^{\circ} \mathrm{C}$ for $72 \mathrm{~h}$} \\
\hline Tensile strength & -31.8 & -10.2 & -13.0 & -4.6 & .4 .3 & -9.2 & 6.2 & -4.2 & 1.9 \\
\hline Elongation at break & -39.2 & -21.2 & -33.3 & -23.3 & -14.4 & -23.7 & -11.6 & -20.1 & -6.6 \\
\hline Hardness & 5 & 0 & 1 & 0 & 2 & 11 & 1 & 1 & 0 \\
\hline
\end{tabular}

It is clear from Table 4 that, all EPDM based vulcanizates have superior thermal aging resistance than NR reference. Although there are some disordered results; this effect is especially more evident for aging at $100^{\circ} \mathrm{C}$. For $70^{\circ} \mathrm{C}$, it is possible to say that traditional EPDM (EPDM-0) is almost unaffected by thermal aging. If two EPDM types are compared in each other for both aging temperature, EPDM-A and derivative formulations exhibit slightly higher deterioration in physical and mechanical properties (especially in tensile strength) after aging. This is assigned to quite low branched a molecular structure of alternative EPDM; linear backbone is thought to be exposed to main chain scission instead of branches, and so deterioration is more appreciable than that of traditional EPDM. Oil incorporated EPDM-A formulations have better aging resistance than that of EPDM-A, even there is no systematic evolution. This is attributed to better filler distribution in the compounds. Low sulphur ratio provides 
higher retention in the properties. Here, this indicates to be deliberate on sulphur ratio selection considering both aging and dynamic properties. Indeed, lower amount of short sulphur crosslinks provides better aging resistance while long ones do better dynamic properties.

Compression set test give important information about successive service temperatures of the final products. Therefore, in this study, compression set test temperatures were selected as $23^{\circ} \mathrm{C}, 70^{\circ} \mathrm{C}$, and $100^{\circ} \mathrm{C}$ for evaluating a wide range duration performance of the vulcanizates; test results are given in Figure 1. When ambient compression set results are compared, all the vulcanizates have similar behaviour except EPDM-0 formulation. However, all EPDM vulcanizates are found to be resistant to compressive deformation in high test temperatures. For example, NR-60 vulcanizates was deformed as $88 \%$ more than EPDM-A at $70^{\circ} \mathrm{C}$; this deformation is also $168 \%$ more at $100^{\circ} \mathrm{C}$. Compression at $70^{\circ} \mathrm{C}$ caused a $134 \%$ less decrease in thickness of EPDM-A relative to EPDM-0 and $45 \%$ less decrease than NR-60. These ratios are $45 \%$ and $167 \%$ respectively for $100^{\circ} \mathrm{C}$. Consequently, alternative EPDM exhibits its thermal aging resistance and high elasticity together for high aging temperatures; it becomes prominent among two different EPDM types with 1/3 times good compression durability. This property is assigned to an important issue for new generation high temperature dynamic applications. Oil incorporation has a slight unfavorable effect on these good properties. If we compare the effect of sulphur ratio on compression set properties of the vulcanizates, it is clearly seen that high temperature compression set increases for high sulphur containing vulcanizates. This is attributed to that further amount of long sulphur crosslinks, in other words providing higher S-S/C-S crosslink ratio, cause more dominant crosslink scission at high aging temperatures. This effect can also be defined as lower elastic properties for the related vulcanizates.

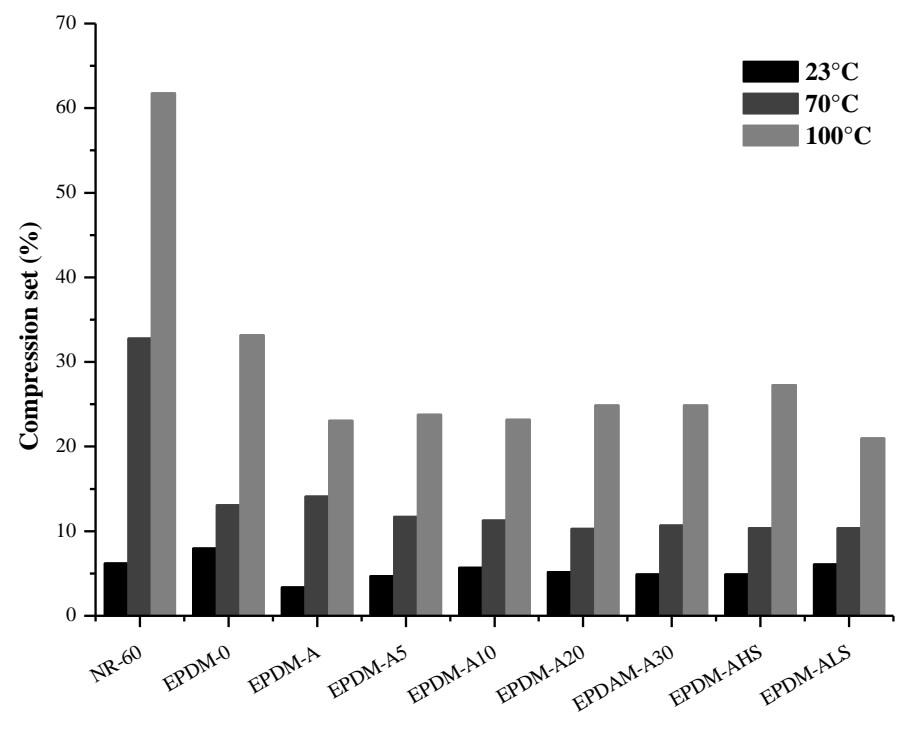

Figure 1. Compression set test results for various aging temperatures

Ozone resistance is one of the distinguishing features of EPDM. It is well known that traditional EPDMs have satisfactory ozone resistance due to saturated backbone. Alternative EPDM and its derivative formulations have been tested against ozone at the conditions $25^{\circ} \mathrm{C}, 60 \%$ relative humidity, and 200 pphm ozone concentration. Aged samples are shown in Figure 2. As it is seen from the figure, all the EPDM based formulations are ozone resistant while NR-60 formulation has deep cracks. Therefore, it is concluded that alternative EPDM has the same durability for ozone aging as well as traditional EPDM. This result is valid even it contains process oil and various amount of sulphur. 


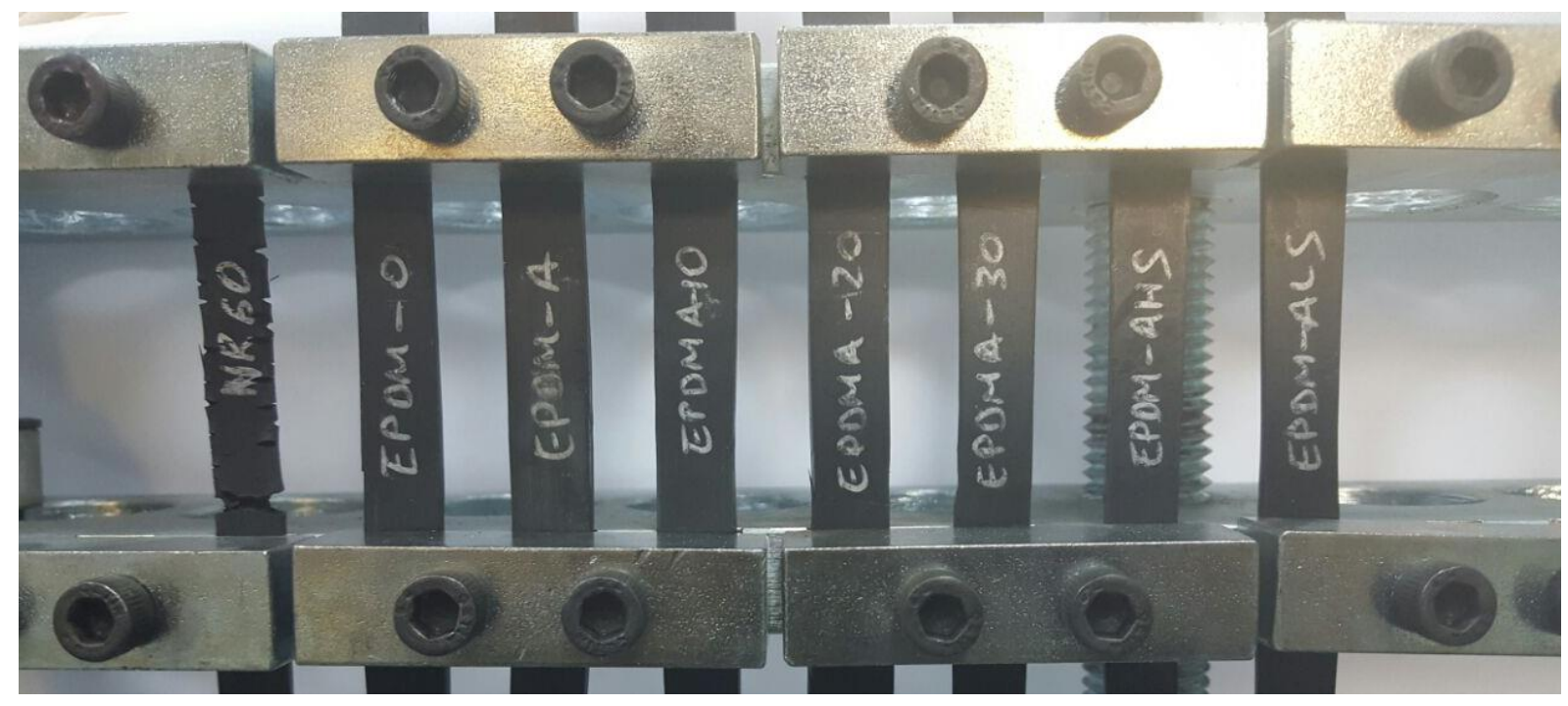

Figure 2. Vulcanizate samples after ozone aging

\subsection{Dynamic Properties}

In this study, dynamic properties of the vulcanizates have been evaluated in terms of three methods: rebound resilience test, Goodrich flexometer test, and tan delta measurements via dynamic-mechanical analysis. Rebound resilience test method is suitable for a rough assessment of dynamic behaviour of rubber the vulcanizates by using simple equipment. When rubber is deformed, it absorbs energy that is partly recovered when it regains its original shape. Energy that is not returned as mechanical energy is dissipated as internal energy of the test specimen. Figure 3 shows that EPDM-A exhibits superior rebound resilience as 15\% higher than NR and 2 times higher than EPDM-0. That EPDM-A may be an assertive competitor to NR is clear from the rebound resilience test results. Higher amount of crosslinks in EPDM-AHS vulcanizate provides improved dynamic properties. This is attributed to the advantages of conventional vulcanization system, with longer crosslinks and so improved fatigue properties.

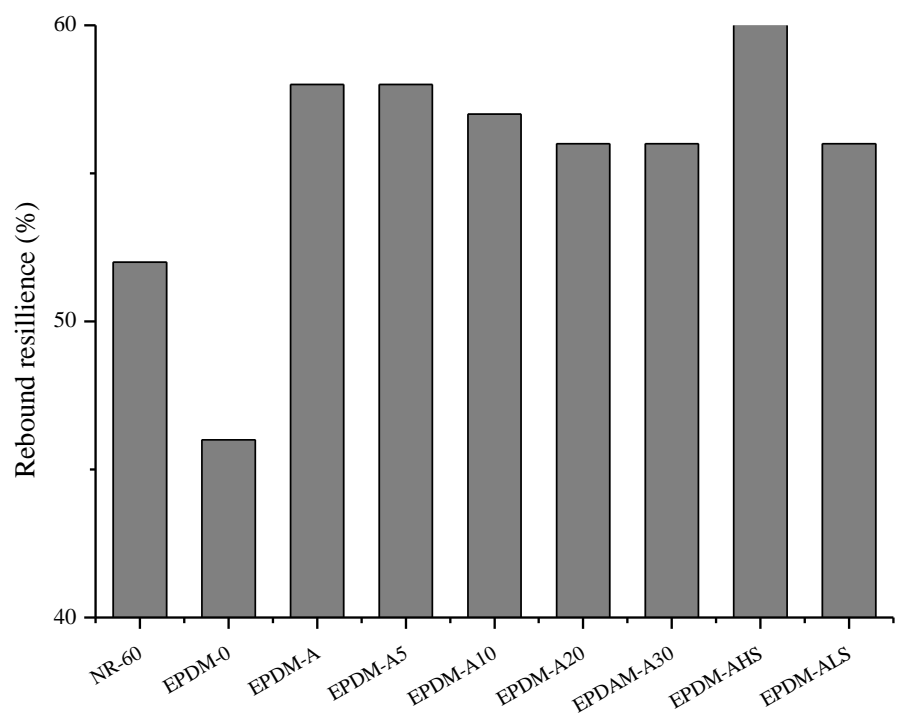

Figure 3. Rebound resilience (\%) of all the vulcanizates

Rubber based materials tend to be deformed by oxidation and dynamic fatigue. Besides, heat build-up during dynamic application accelerates this tendency and causes earlier fracture of the material. 
Goodrich flexometer is a basic simulation of fatigue in dynamic conditions; this test gives valuable information about heat build-up behavior of the rubber based material for making possible predictions regarding real time performance conditions. Temperature increase and internal temperature values of the vulcanizates at the end of the standard Goodrich cycle are given in Figure 4. It is clear from the figure that, all EPDM formulations exhibit improved performance in terms of both temperature increase and internal temperature on Goodrich flex test. Furthermore, EPDM-A formulation and its derivatives provide lower heat build-up than that of traditional EPDM formulation. When NR-60 and EPDM-A vulcanizates are compared, 25\% improvement is conspicuous; EPDM-A vulcanizate has also 20\% lower internal temperature at the end of the test.

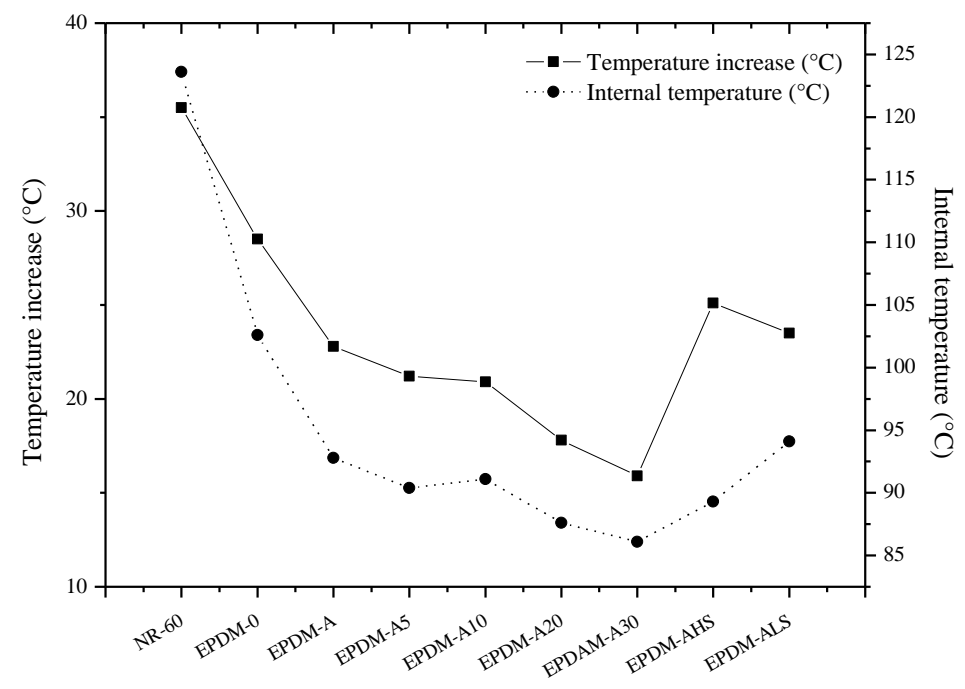

Figure 4. Temperature increase and internal temperatures of the vulcanizates after complete Goodrich flexometer test

Oil incorporation to EPDM-A improves heat build-up, proportionally. This result was confirmed by temperature increase measurements. In EPDM-ALS formulation, it has revealed that low sulphur ratio in curing system could not provide the same heat built results most likely due to shorter sulphur crosslinks. In EPDM-AHS formulation, internal temperature was measured as $3.5^{\circ} \mathrm{C}$ lower relative to EPDM-A whereas temperature increase is $2.3^{\circ} \mathrm{C}$ higher than that of the same reference point. This is an unexpected variation and difficult to understand with fundamental knowledge in fatigue resistance and amount of crosslinks for high sulphur loadings. Effect of sulphur ratio on crosslink types and chemical stability of the crosslinks are another issue to clarify; but this issue could not have been integrated into the present study. Meanwhile, it should be into consideration that, length of sulphur crosslinks has a direct effect on thermal aging resistance of the vulcanizates; this situation is an important concern to adjust long term performance of the final rubber product.

Dynamic mechanical analysis, otherwise known as DMA, is a technique where a small deformation is applied to a sample in a cyclic manner. This allows the material response to stress, temperature, frequency, and other values to be studied. DMA is a high precision technique for measuring the viscous and elastic behaviors separately, for viscoelastic materials such as rubber. Most important viscoelastic property for the materials under dynamic effect is damping, which is represented by tangent delta (tan $\delta$, loss factor). It is a measure of how well a rubber material can get rid of energy. NR has $\tan \delta$ values even at relatively higher temperatures. This is an advantage for dynamic applications. However, NR is rapidly aged at temperatures over the temperatures which commonly used new generation dynamic applications. This is the reason to measure $\tan \delta$ values of selected vulcanizates especially for elevated temperatures. 
DMA test results are given for two different modes. In Figure 5, temperature sweep data of selected formulations was compared. As it can be seen from Figure 5, EPDM-A formulation gives relatively lower tan $\delta$ than both NR and EPDM based reference formulations at either low or high temperatures. This is an important finding to indicate a wide range high performance of EPDM-A. In addition, decrease in $\tan \delta$ values of EPDMs at higher temperatures is attributed to post cure behavior of EPDM and improved elastic properties. For $5 \mathrm{phr}$ oil incorporation to EPDM-A formulation, lower $\tan \delta$ value is intuitively assigned to better filler dispersion in the compound.

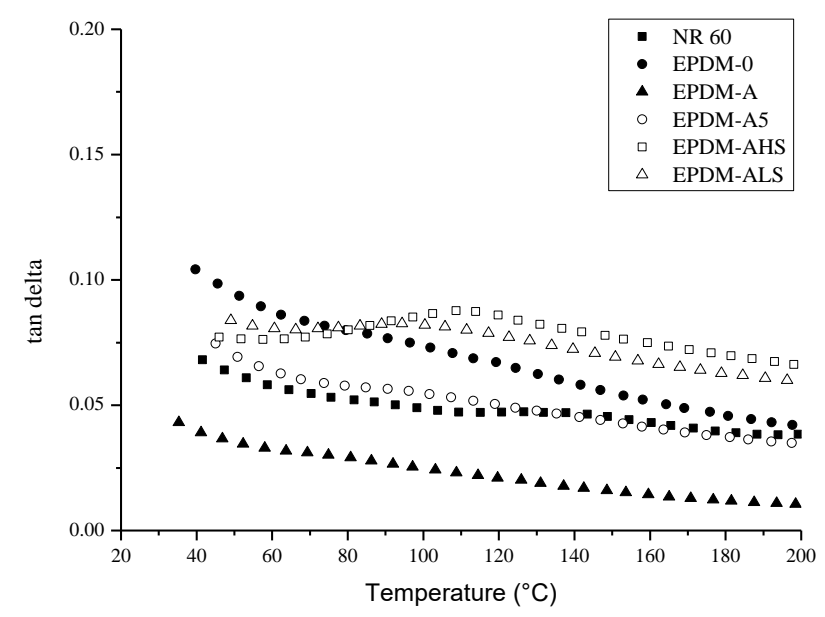

Figure 5. Temperature sweep $\tan \delta$ values for selected vulcanizates

Frequency sweep test was performed for a common range $(1-100 \mathrm{~Hz})$ for simulating mild and hard dynamic conditions for a rubber material. Test temperature was specified as $60^{\circ} \mathrm{C}$ representing average working temperature for various dynamic applications. As it is seen from Figure 6, traditional EPDM has the highest $\tan \delta$ values for all the frequencies; NR-60 follows traditional EPDM. Alternative EPDM based EPDM-A formulation exhibits the lowest tan $\delta$ values among simple formulations. This finding is quite important for wide application range for alternative EPDM. EPDM-A and EPDM-A5 formulations have very close $\tan \delta$ values for low and moderate frequencies; but also EPDM-A5 exhibits better dynamic performance for high frequencies. This advantageous behavior is intuitively attributed to better filler dispersion in the presence of additional process oil. Besides these, EPDM-AHS, which has high sulphur content, has the lowest $\tan \delta$ due to its more elastic behavior as stated before.

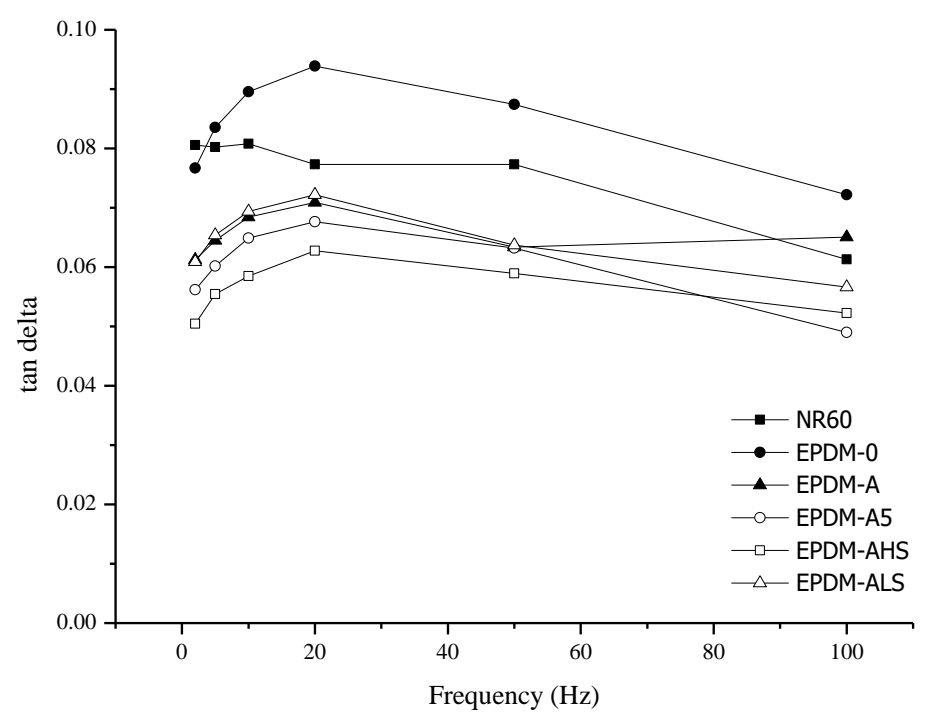

Figure 6. Frequency sweep $\tan \delta$ values for selected vulcanizates 


\subsection{Low Temperature Properties}

Temperature retraction test results for selected vulcanizates are given in Figure 7. According to the figure, alternative EPDM based formulations have very closed low temperature behaviors. This means that oil content and different sulphur loadings do not affect the temperature retraction behavior of the final material. However, retraction characteristics strongly depend on the rubber type. EPDM-0 is slower than NR for low retraction ratios while it is the fastest vulcanizate for higher retraction ratios. In other words, EPDM-0 starts to its retraction later than NR, but it also retains its original shape faster. EPDMA vulcanizate exhibits the latest retraction among all. For instance, when EPDM-0 returns to $70 \%$ of its original shape, EPDM-A can do \% 15 . Indeed, this behavior is an upgradable property by using special process oils and additives.

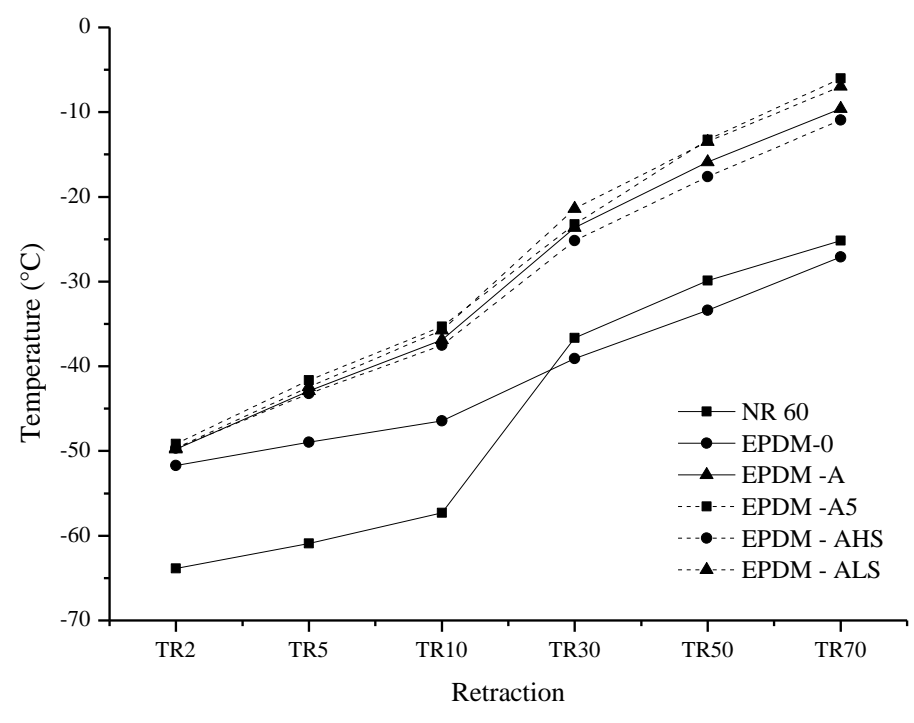

Figure 7. Temperature-retraction relations of selected vulcanizates

\section{CONCLUSION}

In this study, EPDM has been evaluated as a raw material for high temperature dynamic applications. Basically NR, traditional EPDM, and a special grade EPDM have been used for preparing alternative compounds. Rheological, mechanical, dynamic-mechanical, aging, and low temperature properties of the samples were compared. Tensile strength values of new generation EPDM based formulations have been found between traditional NR and EPDM based formulations as well as tear strength tended to decrease. Alternative formulations have superior set resistance to compression, especially at high temperatures. This finding is quite valuable for extending the temperature range of successful dynamic applications. High aging retention in mechanical properties is another advantage of alternative EPDM, relative to traditional NR based formulations. Dynamic performance was absolutely the most important property of the formulations that were focused on. Excellent rebound resilience of the alternative EPDM based materials has indicated better dynamic performance. Internal temperature after complete Goodrich flexometer test could be decreased as $25 \%$ relative to NR reference. DMA test results have also indicated considerably better damping properties of new generation EPDM, for both a wide temperature range and a wide frequency range. Indeed, hard processing conditions and difficult filler distribution were noticed for alternative EPDM based compounds. However, this has been overcome by using small amount of additional process oil, without significant loss in overall properties. It was concluded that, new generation ultra-high molecular weight and linear EPDM grade is an assertive competitor to NR for a wide range dynamic applications. 


\section{REFERENCES}

[1] Harris CM, Piersol AG. Mechanical properties of rubber. In: Schafer C, editor. Shock and Vibration Handbook. New York, USA: McGraw Hill, 2002.

[2] Dick JS. How to Improve Rubber Compounds? 1st ed. Munich, Germany: Hanser, 2014.

[3] Sommer JG. Troubleshooting Rubber Problems. 1st ed. Munich, Germany: Hanser, 2013.

[4] Stratton A, Ferry D. Mechanical properties of natural rubber vulcanizates crosslinked by various agents. J Physic Chem 1963; 67: 2781-2785.

[5] Fan L, Zhang Y, Li F, Zhang X, Sun K, Fan Z. Effect of high temperature curing on the crosslink structures and dynamic properties of gum and N 330 - filled natural rubber vulcanizates. Polym Test 2001; 20: 925-936.

[6] Simma K, Rempel L, Prasassarakich P. Improving thermal and ozone stability of skim natural rubber by diimide reduction. Polym Degrad Stab 2009; 94: 1914-1923.

[7] Akinlabi K, Okieimen E, Aigbodion I. Thermal ageing properties and chemical resistance of blends of natural rubber and epoxidized low molecular weight natural rubber. J Appl Polym Sci 2001; 98: 1733-1739.

[8] Lu X, Yang Y, Cheng B. High damping epoxidized natural rubber/diallyl phtalate prepolymer (ENR/DAP-A) blends engineered by interphase crosslinking. J Appl Polym Sci 2018; doi: 10.1002/app.46300.

[9] Markovic G, Dutta K, Dimopoulos M, Choudhury R, Matisons JG. Viscoelastic behaviour of filled and unfilled EPDM elastomer. Thermochim Acta 1999; 357: 211-216.

[10] Mao X, Xu S, Wu C. Dynamical mechanical properties of EPDM rubber blends. Polym Plast Technol Eng 2008; 47: 209-214.

[11] Nabil H, Ismail H, Azura AR. J Vinyl Addit Technol 2015; 21: 79-88.

[12] Hintze C, Stocek R, Horst T, Jurk R, Wiessner S, Heinrich G. Polym Eng Sci 2014; 54: 2958-2964.

[13] Spanos P, Beelen J, Gögelein C, Duin M, Aar N. NR Replacement by ultra-high molecular weight EPDM in dynamic applications. In: 188th Technical Meeting of the Rubber Division ACS, 12-14 October 2015; Cleveland, USA. 